\title{
Psychological Aspects of The Creative Crisis
}

Babaeva Yulia, Phd, senior researcher

Varvaricheva Yana

Lomonosov MSU, psychological faculty

The phenomenon of creative crisis hasn't been sufficiently studied in modern psychology, despite the relevance of its empirical and theoretical investigation.

The importance of its analysis is justified by serious implications creative crisis has on a person: they range from sense of weakness to loss of creative work's meaning, ability to proceed, self-harm and suicide. Its phenomenology was covered in biographies, history of art, literary studies etc. We can find vivid descriptions in letters and diaries of the great ones.

"Why did you forget, my good friend, about the state of the ever-increasing mental impotence in which I find myself? $<. .>$ Music requires fresh thoughts, but I have nothing but fatigue and hydrophobia."

(From G.Rossini's letter to D.Donzelli. October 30, 1852;

G. Rossini stopped publishing his music pieces in 1829).

Here we try to summarize the research on the creative crisis phenomenon that we've been conducting in the Russian sample for several years. We collected and analyzed extensive phenomenological data: implicit ideas about creativity, descriptions of creative crises experience (including metaphors of creativity and crises), descriptions of emotional experience and process of coping with the crisis. Total sample included more than 200 subjects.

We formed a set of methods, which provide deep and complete investigation of creative crises. In addition to interviewing, it included Rokeach Value Survey; COPE Inventory, the Grounded Theory method (its prospects were substantiated in a study with V.Mazanova); and original techniques: "Symbol of creativity" and "Life line" modification for creative biography analysis.

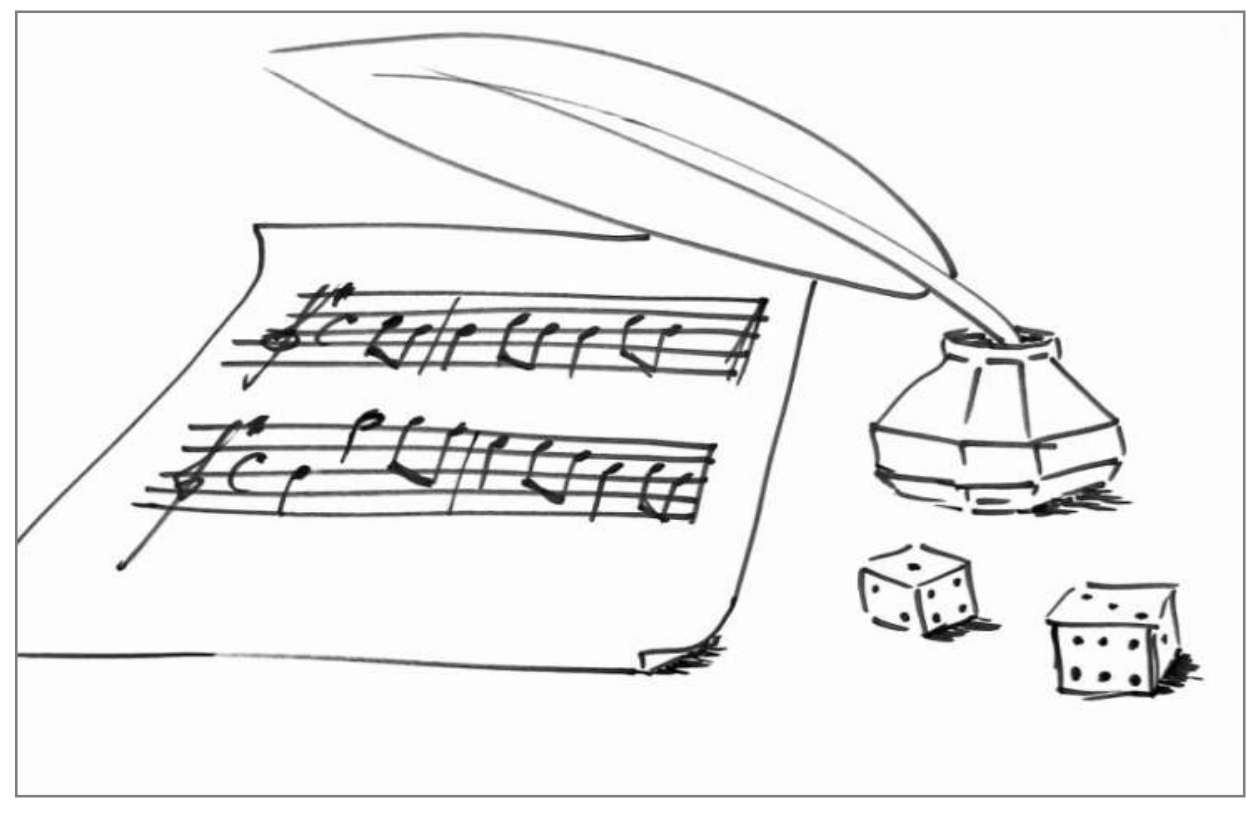

Musician no longer working in music (age 38) "Great pieces of art often appear due to chance"

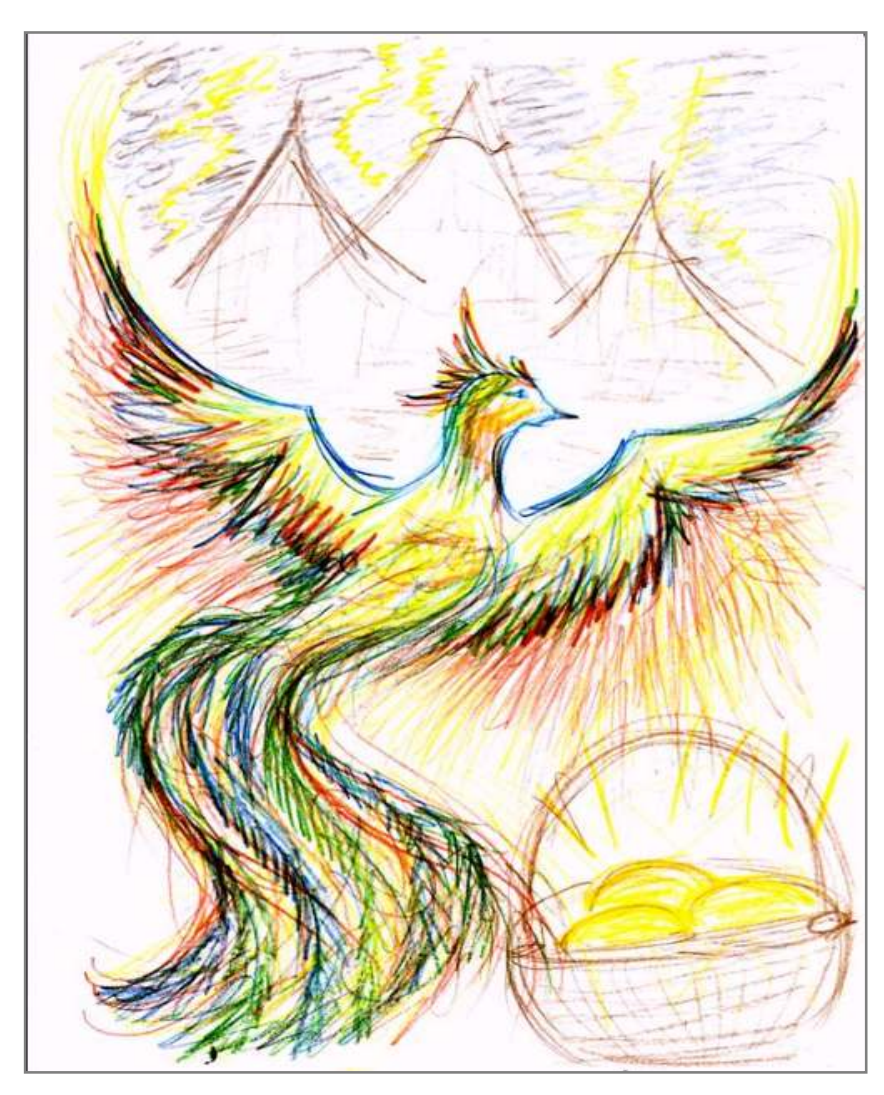

Examples of "Symbol of creativity" technique This projective method accompanied by interview is aimed to discover implicit beliefs about creativity, its role in one's life, mechanisms of its development and functioning etc. This information turns out to be important for understanding the origins of creative crisis and the resources for coping with it.
Alongside with negative features we identified a number of

positive functions of creative crises, important for its successful overcoming.

Signal: crisis is a "timely warning of trouble", an indicator of the danger of "losing yourself", "betraying one's destiny".

Diagnostic: "checking oneself for strength and resilience", assessment of one's personal qualities, which, in the opinion of the respondent, are necessary to fight the difficulties.

Developmental (stimulating): crisis as an incentive for progress, as well as a kind of "hardening" necessary for the creative personality development.

Protective: a crisis as a necessary, though painfully experienced, "falling out of the creative process", a "temporary respite" that allows you to gather strength and concentrate before a new spurt.

Creative: crisis as an important stage in creative person's life, at which not only reestimation of one's values, goals and achievements takes place but also the search for new directions in creative activity begins.

Self-report considering positive functions of creative crisis indicated some resource for coping and overcoming it. For example respondents who noted the developmental and signal functions considered that the crisis could contribute to the transformation of values, motives, goals, meaningful formations, evaluation criteria, rise of new ideas.

\section{Other results.}

- Significant variances in value of creativity were found for different groups of subjects (involved in creative activity and those who quitted; authors and performers)

- Approaches to creative crises classification were proposed. The differentiation of two main stages of creativity (the creative plan and its implementation) suggests the existence of two types of creative crises. The 1st was designated as a "crisis of inspiration". The person experiencing it suffers due to a dramatic decrease in creative activity and the lack of new ideas. The creative crisis of the 2nd type, "crisis of incarnation", arises when the realization of the author's idea is impossible or difficult, and also when the result does not correspond to the original plan.

- Coping strategies and their contribution to creative crises' overcoming were investigated (with A. Sudyarova). Correlation analysis showed that successful overcoming of "incarnation crisis" is positively connected with active coping and planning. However, the successful overcoming of "inspiration crisis" is associated with the adoption of situation. In general, our studies show that creative crises' overcoming depends on the type of crisis, and on the subject's personal characteristics. The latter include biographical creative experience, including events of early childhood; subject's implicit ideas about crises and creativity; locus of control; preferred coping strategies; value orientations; understanding of creative crisis' positive functions. The research contributes to the enhancement of psychological support for representatives of creative professions and the prevention of creative crises' negative effects.

Contact: julybabaeva@gmail.com copyright $₫ 2019$ Babaeva Yu.D. varvaricheva Y.I. 